\title{
Efeitos de doses de nitrogênio e potássio aplicadas por fertirrigação no meloeiro
}

\author{
Valdemício F. de Sousa' ${ }^{1}$ Eugênio F. Coelho², Valdomiro A. B. de Souza ${ }^{1} \&$ Roberto S. F. de Holanda Filho ${ }^{1}$ \\ 1 EMBRAPA Meio-Norte, Av. Duque de Caxias 5650, Bairro Buenos Aires. CP 01, CEP 64006-220-Teresina, PI. Fone: \\ (86) 225 1141. E-mail: vfsousa@cpamn.embrapa.br (Foto); valdo@cpamn.embrapa.br; robertosilvio2002@yahoo.com.br \\ ${ }^{2}$ EMBRAPA Mandioca e Fruticultura, Rua EMBRAPA s/n, CP 007, CEP 44380-000. Cruz das Almas, BA. E-mail: \\ ecoelho@cnpmf.embrapa.br
}

Protocolo $76-6 / 5 / 2003$ - Aprovado em 14/1/2005

\begin{abstract}
Resumo: Objetivou-se, com este trabalho, avaliar os efeitos de quatro doses de nitrogênio e quatro de potássio aplicadas via água de irrigação por gotejamento no meloeiro cultivado em solo arenoso dos Tabuleiros Costeiros do Piauí. O experimento foi realizado no Campo Experimental da EMBRAPA Meio-Norte, em Parnaíba, PI, Brasil $\left(3^{\circ} 5^{\prime} \mathrm{S}\right.$ e $41^{\circ} 47^{\prime} \mathrm{W}$ ). Utilizou-se o delineamento experimental em blocos ao acaso, em fatorial $4 \times 4$, com 3 repetições. Foram testadas as doses de $100,160,220$ e $280 \mathrm{~kg} \mathrm{ha}^{-1}$ de $\mathrm{N}$ e 100, 190, 280 e $370 \mathrm{~kg} \mathrm{ha}^{-1}$ de $\mathrm{K}_{2} \mathrm{O}$. A matéria seca, peso médio de frutos e a produtividade comercial do meloeiro, foram influenciados pelas dosagens de $\mathrm{N}$ e $\mathrm{K}_{2} \mathrm{O}$ e a interação entre elas, enquanto a área foliar o foi apenas pelas doses de $\mathrm{N}$. Os maiores valores de matéria seca $\left(93 \mathrm{~g}_{\text {planta- }}{ }^{-1}\right)$, peso médio de frutos $(1,85 \mathrm{~kg})$ e a produtividade comercial $\left(48,13 \mathrm{t} \mathrm{ha}^{-1}\right)$ foram obtidos com as combinações de 100 e $190 \mathrm{~kg} \mathrm{ha}^{-1}, 220$ e $190 \mathrm{~kg} \mathrm{ha}^{-1} \mathrm{e}, 100$ e $370 \mathrm{~kg} \mathrm{ha}^{-1}$ de $\mathrm{N}$ e $\mathrm{K}_{2} \mathrm{O}$ respectivamente. $\mathrm{O}$ índice mais elevado de área foliar $\left(12.017,40 \mathrm{~cm}^{2}\right.$ planta $^{-1}$ ) foi registrado com a aplicação de $100 \mathrm{~kg} \mathrm{ha}^{-1}$ de N. A aplicação de 100 a $160 \mathrm{~kg} \mathrm{ha}^{-1}$ de $\mathrm{N}$ com $370 \mathrm{~kg} \mathrm{ha}^{-1}$ de $\mathrm{K}_{2} \mathrm{O}$ proporcionou as maiores produtividades comerciais do meloeiro.
\end{abstract}

Palavras-chave: Cucumis melo, nutrição de planta, gotejamento

\section{Effect of nitrogen and potassium doses applied by fertirrigation in a melon crop}

\begin{abstract}
The objective of this work was to evaluate the effect of four doses of nitrogen (N) and four doses of potassium $\left(\mathrm{K}_{2} \mathrm{O}\right)$ applied through drip irrigation in the melon cultivated in a sandy soil of Costal Tablelands of Piauí. The experiment was carried out at the experimental area of EMBRAPA

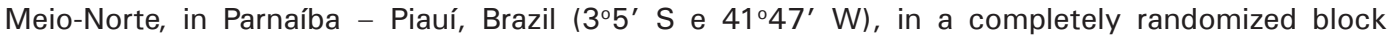
design, in $4 \times 4$ factorial with three repetitions. The doses used were: 100, 160, 220 and $280 \mathrm{~kg} \mathrm{ha}^{-1}$ of $\mathrm{N}$ and $100,190,280$ and $370 \mathrm{~kg} \mathrm{ha}^{-1}$ of $\mathrm{K}_{2} \mathrm{O}$. The dry matter production, mean weight of the fruit and commercial yield of melon were influenced by $\mathrm{N}$ and $\mathrm{K}_{2} \mathrm{O}$ doses and the interaction between them. The leaf area was influenced by nitrogen dose only. The higher values of dry matter production $\left(93 \mathrm{~g} \mathrm{plant}^{-1}\right)$, average fruit weight $(1.85 \mathrm{~kg})$ and commercial yield of melon $(48.13 \mathrm{t}$ $\mathrm{ha}^{-1}$ ) were obtained with $\mathrm{N}$ and $\mathrm{K}_{2} \mathrm{O}$ doses of 100 and $190 \mathrm{~kg} \mathrm{ha}^{-1}, 220$ and $190 \mathrm{~kg} \mathrm{ha}^{-1}$ and 100 and $370 \mathrm{~kg} \mathrm{ha}^{-1}$, respectively. The highest leaf area $\left(12,017.40 \mathrm{~cm}^{2}\right.$ planta-1) was registered with the application of $100 \mathrm{~kg} \mathrm{ha}^{-1}$ of $\mathrm{N}$. Dose of 100 and $160 \mathrm{~kg} \mathrm{ha}^{-1}$ of $\mathrm{N}$ in combination with $370 \mathrm{~kg} \mathrm{ha}^{-1}$ of $\mathrm{K}_{2} \mathrm{O}$ produced the maximam commercial yield of melon.
\end{abstract}

Key words: Cucumis melo, plant nutrition, drip irrigation

\section{INTRODUÇÃO}

O meloeiro (Cucumis melo L.) é bastante exigente com relação ao solo, principalmente no que diz respeito à fertilidade e à acidez. A literatura mostra que essa cultura pode ser explorada em diferentes tipos de solo; todavia, aqueles de textura franco-arenosa, areno-argiloso, leves, soltos, profundos e bem drenados, com pH variando entre 6,4 e 7,2, são considerados os mais adequados.

A avaliação do crescimento das plantas cultivadas precisa ser feita, pois permite inferir-se a atividade fisiológica de plantas geneticamente diferentes e/ou desenvolvidas em ambientes diferentes (Benincasa, 1988). Embora seja uma técnica importante, poucas são as referências na literatura que abordem 
os parâmetros de crescimento em plantas de meloeiro relacionando, sobretudo, os efeitos de diferentes doses de nutrientes.

Sob condições de adubação convencional, Belfort (1985) verificou que o crescimento do meloeiro é lento nas primeiras semanas, intensificando-se posteriormente, com pico entre 30 e 45 dias após a emergência das plantas. Graifenberg \& Petsas (1983) registraram maior velocidade no crescimento do meloeiro entre 30 e 40 dias após o plantio; já Tyler \& Lorenz (1964) constataram que a maior velocidade no crescimento em melão foi entre 70 e 80 dias após a emergência das plantas, correspondendo ao início da floração.

Bhella \& Wilcox (1989) verificaram que com o aumento da dose de $\mathrm{N}$ a área foliar do meloeiro aumentou sensivelmente; entretanto, o crescimento das plantas e a produção de frutos aumentaram com a redução da dosagem de nitrogênio aplicada.

Estudando o efeito da fertirrigação e de freqüências de aplicação de nitrogênio e de potássio nos parâmetros de crescimento do meloeiro em Botucatu, SP, Sousa (1993) constatou que o maior acúmulo de matéria seca foi registrado entre 26 e 36 dias após o transplantio das mudas e, ainda, que a taxa de crescimento tende a reduzir com a idade das plantas.

O nitrogênio é elemento importante para a nutrição do meloeiro. $\mathrm{O}$ efeito da adubação nitrogenada nessa cultura, de acordo com Faria (1990) e Katayama (1993), é resultado do aumento no número e peso dos frutos. $\mathrm{O}$ aumento da dosagem de nitrogênio até $67 \mathrm{~kg} \mathrm{ha}^{-1}$, elevou a área foliar do meloeiro, o que influencia a produção de fotoassimilados e, conseqüentemente, o aumento na produção de frutos (Bhella \& Wilcox, 1986).

Em trabalho realizado por Brantley \& Warren (1961) verificou-se que a aplicação de altas doses de nitrogênio no meloeiro provocou florescimento abundante e frutificação precoce, contribuindo para a redução na produtividade de frutos comerciais. Williams (1978) registrou um aumento significativo na produtividade no meloeiro quando elevou a dose de $\mathrm{N}$ para $280 \mathrm{~kg} \mathrm{ha}^{-1}$. Entretanto, de acordo com os resultados obtidos por Bhella \& Wilcox (1989) e Suarez (1991), o rendimento dessa cultura decresceu com o aumento da quantidade de nitrogênio aplicada.

Além do nitrogênio, o potássio exerce grande influência na produção, em especial na qualidade de frutos do meloeiro, pois este elemento exerce papel importante na translocação de carboidratos para os frutos (Prabhakar et al., 1985); contudo, existem resultados controversos, tanto quanto seu efeito isolado, quanto na interação com nitrogênio. Jassal et al. (1971) constataram aumento na produtividade do meloeiro com o aumento na dose de potássio e que a interação nitrogênio potássio promoveu aumento no peso médio de frutos.

Dados experimentais e informações na literatura são contraditórios em relação às doses de nutrientes para o meloeiro, mesmo em sistema convencional de adubação. Com o surgimento da fertirrigação no Brasil, Pinto et al. (1997) destacam a necessidade de se determinar doses ótimas de nutrientes a serem aplicadas via água de irrigação para cada cultura. Dentre as técnicas utilizadas para aplicação de fertilizantes às plantas, a fertirrigação proporciona melhor distribuição dos nutrientes durante o ciclo da cultura; permite aplicações parceladas de nutrientes, favorece menor perda de nutrientes por lixiviação e sua melhor distribuição no volume de solo explorado pelas raízes da cultura (Sousa, 1993).

Trabalhos de pesquisa, como os realizados por Hernandez \& Aso (1991) e Pinto et al. (1997) têm mostrado que a maior produtividade do meloeiro pode ser obtida com níveis crescentes de nutrientes aplicados via água de irrigação; portanto, é necessário se definir as melhores doses de nutrientes para o meloeiro em regime de fertirrigação.

Objetivou-se, com este trabalho, avaliar os efeitos de quatro doses de nitrogênio e quatro de potássio aplicadas via água irrigação por gotejamento, no meloeiro cultivado em solo arenoso dos Tabuleiros Costeiros do Piauí.

\section{MATERIAL E MÉTODOS}

O experimento foi conduzido no campo experimental da EMBRAPA Meio-Norte, localizado no município de Parnaíba, PI, Brasil ( $3^{\circ} 5^{\prime}$ S; 41 ${ }^{\circ} 47^{\prime} \mathrm{W}$ e 46,8 m). A região apresenta clima úmido do tipo Aw', precipitação média anual de $1.300 \mathrm{~mm}$, umidade relativa média do ar de $75 \%$, temperatura média de $27^{\circ} \mathrm{C}$ e velocidade do vento variando de 2 a $5 \mathrm{~m} \mathrm{~s}^{-1}$ (Bastos et al., 2000). Os solos da área experimental pertencem às unidades de mapeamento Neossolos Quartzarênicos (EMBRAPA, 1999). As características do solo foram: a) físico-hídricas: areia grossa $\left(420 \mathrm{~g} \mathrm{~kg}^{-1}\right)$, areia fina $\left(370 \mathrm{~g} \mathrm{~kg}^{-1}\right)$, silte $\left(110 \mathrm{~g} \mathrm{~kg}^{-1}\right)$, argila $(100$ $\left.\mathrm{g} \mathrm{kg}^{-1}\right)$, densidade do solo $\left(1,60 \mathrm{~kg} \mathrm{dm}^{-3}\right)$ e capacidade de campo $\left(0,095 \mathrm{~cm}^{3} \mathrm{~cm}^{-3}\right)$; b) fertilidade: matéria orgânica $\left(9,30 \mathrm{~g} \mathrm{~kg}^{-1}\right)$, $\mathrm{pH}(6,48), \mathrm{P}\left(4,7 \mathrm{mg} \mathrm{kg}^{-1}\right), \mathrm{K}\left(25,03 \mathrm{mg} \mathrm{kg}^{-1}\right), \mathrm{Ca}\left(18,00 \mathrm{mmol}_{\mathrm{c}} \mathrm{kg}^{-1}\right)$, $\mathrm{Mg}\left(8,00 \mathrm{mmol}_{\mathrm{cg}}^{-1}\right), \mathrm{Na}\left(0 \mathrm{mmol} \mathrm{kg}^{-1}\right), \mathrm{Al}\left(0 \mathrm{mmol} \mathrm{kg}^{-1}\right), \mathrm{H}+\mathrm{Al}$ $\left(6,4 \mathrm{mmol}_{\mathrm{c}} \mathrm{kg}^{-1}\right), \mathrm{S}\left(26,6 \mathrm{mmol}_{\mathrm{c}} \mathrm{kg}^{-1}\right), \mathrm{CTC}\left(33,0 \mathrm{mmol} \mathrm{kg}^{-1}\right), \mathrm{V}$ $(80,60 \%)$ e m $(0 \%)$.

O preparo da área consistiu de uma aração a $20 \mathrm{~cm}$, duas gradagens, sulcamento e adubação orgânica e química. Após a aração e gradagens, foram confeccionados sulcos de plantio espaçados $2 \mathrm{~m}$ e profundidade de $15 \mathrm{a} 20 \mathrm{~cm}$. A adubação de fundação foi feita em sulco, aplicando-se e incorporando $200 \mathrm{~g}$ $\mathrm{m}^{-1}, 17 \mathrm{~g} \mathrm{~m}^{-1}, 4 \mathrm{~g} \mathrm{~m}^{-1}$ e $8 \mathrm{~L} \mathrm{~m}^{-1}$ de superfosfato triplo, cloreto de potássio, FTE-BR12 e esterco de curral, respectivamente.

Utilizou-se a cultivar Eldorado 300, no espaçamento de 2,00 $\mathrm{x} 0,20 \mathrm{~m}$. As plantas cresceram espontaneamente, sem nenhum sistema de condução de ramos ou desbrota. O delineamento experimental utilizado foi o blocos ao acaso em esquema fatorial, com três repetições. As doses de nitrogênio $(\mathrm{N})$ e potássio $\left(\mathrm{K}_{2} \mathrm{O}\right)$ foram: 100, 160, 220 e $280 \mathrm{~kg} \mathrm{de} \mathrm{N} \mathrm{ha}^{-1}$ e 100, 190, 280 e 370 $\mathrm{kg}$ de $\mathrm{K}_{2} \mathrm{O} \mathrm{ha}^{-1}$, nas formas de uréia e cloreto de potássio, respectivamente. $\mathrm{ON}$ foi aplicado todo em cobertura via água de irrigação e, em relação ao $\mathrm{K}_{2} \mathrm{O}, 50 \mathrm{~kg} \mathrm{ha}^{-1}$, foram aplicados em fundação.

As adubações de cobertura foram feitas via água de irrigação com intervalo de dois dias. Utilizou-se um sistema de irrigação por gotejamento, com emissores espaçados $0,5 \mathrm{~m}$ e vazão nominal de $4 \mathrm{~L} \mathrm{~h}^{-1}$, e um tanque de derivação de fluxo com capacidade para $20 \mathrm{~L}$, para aplicar os fertilizantes. A quantidade de água aplicada foi determinada com base na $\mathrm{ET}_{\mathrm{O}}$ obtida por meio do tanque Classe A e do Kc médio do meloeiro: 0,50, 0,80, 1,0 e 0,70 , referentes aos períodos vegetativo, floração, 
frutificação e maturação, respectivamente (Doorenbos \& Pruitt, 1984).

Para a determinação dos parâmetros de crescimento (matéria seca e área foliar), amostras de plantas foram coletadas aos 8 , $15,22,29,36,43,50,57$ e 64 dias após a emergência das plantas, sendo cada amostra representada por uma planta por parcela. A área foliar foi determinada com um medidor de superfície laminar e a matéria seca foi feita a partir da secagem de raiz, caule, pecíolo, folha, flor e fruto em estufa, a temperatura de $70{ }^{\circ} \mathrm{C}$.

A colheita foi realizada quando os frutos atingiram o ponto de maturação fisiológica, com teores de sólidos solúveis em torno de $8 \%$ ( ${ }^{\circ}$ brix), determinado em campo com refratômetro portátil. A colheita foi feita com intervalo de três dias e teve início 55 dias após a emergência das plantas e término nove dias depois. Consideram-se frutos comerciais aqueles com peso acima de $0,80 \mathrm{~kg}$, formato normal e não estragados.

\section{RESULTADOS E DISCUSSÃO}

A matéria seca do meloeiro foi significativamente influenciada $(\mathrm{P}<0,01)$ pelas doses de nitrogênio $(\mathrm{N}) \mathrm{de}$ potássio $\left(\mathrm{K}_{2} \mathrm{O}\right)$ e pela interação $\left(\mathrm{N}_{\mathrm{x} \mathrm{K}} \mathrm{O}\right)$. O maior acúmulo de matéria seca pelo meloeiro (93 $\mathrm{g}_{\text {planta }}{ }^{-1}$ ) foi obtido com a aplicação de $100 \mathrm{~kg} \mathrm{ha}^{-1}$ de $\mathrm{N}$ e $190 \mathrm{~kg} \mathrm{ha}^{-1}$ de $\mathrm{K}_{2} \mathrm{O}$. Pela comparação das médias (Tabela 1) e se considerando a mesma dose de $\mathrm{N}$, o máximo valor de matéria seca diferiu apenas do valor obtido com a combinação de $100 \mathrm{~kg} \mathrm{ha}^{-1}$ de N com $100 \mathrm{~kg}$ $\mathrm{ha}^{-1}$ de $\mathrm{K}_{2} \mathrm{O}$.

Tabela 1. Valores médios* de matéria seca $\left(\mathrm{g}^{*}\right.$ planta $\left.^{-1}\right)$ do meloeiro submetido a diferentes doses de nitrogênio e potássio, aplicadas por gotejamento

\begin{tabular}{ccccc}
\hline Doses de & \multicolumn{4}{c}{ Doses de $\mathrm{K}_{2} \mathrm{O}\left(\mathrm{kg} \mathrm{ha}^{-1}\right)$} \\
\cline { 2 - 5 } $\mathrm{N}\left(\mathrm{kg} \mathrm{ha}^{-1}\right)$ & 100 & 190 & \multicolumn{1}{c}{280} & \multicolumn{1}{c}{370} \\
\hline 100 & $64,74 \mathrm{Ba}$ & $93,00 \mathrm{Aa}$ & $75,04 \mathrm{ABa}$ & $81,33 \mathrm{ABa}$ \\
160 & $68,65 \mathrm{Aa}$ & $54,25 \mathrm{Ab}$ & $53,96 \mathrm{Aa}$ & $70,12 \mathrm{Aa}$ \\
220 & $71,49 \mathrm{Aa}$ & $73,57 \mathrm{Aab}$ & $50,82 \mathrm{Aa}$ & $65,78 \mathrm{Aab}$ \\
280 & $86,63 \mathrm{Aa}$ & $82,72 \mathrm{Aa}$ & $50,58 \mathrm{Ba}$ & $42,39 \mathrm{Bb}$ \\
\hline *Médias seguidas de letras maiúsculas iguais na horizontal e as seguidas de letras minúsculas na \\
vertical, não diferem $(\mathrm{P}>0,01), \mathrm{CV}=11,29 \%$
\end{tabular}

Com a aplicação da menor dose de potássio $\left(100 \mathrm{~kg} \mathrm{ha}^{-1} \mathrm{de}\right.$ $\mathrm{K}_{2} \mathrm{O}$ ), o acúmulo de matéria seca aumentou com as doses de nitrogênio; no entanto, somente o valor obtido com a dose de $100 \mathrm{~kg} \mathrm{ha}^{-1}$ de N $\left(64,74 \mathrm{~g} \mathrm{planta}^{-1}\right)$ diferiu das demais. Esta tendência não foi verificada quando as doses de potássio foram aumentadas para 280 e $370 \mathrm{~kg} \mathrm{ha}^{-1}$ de $\mathrm{K}_{2} \mathrm{O}$, cuja redução na matéria seca ocorreu com o aumento das dosagem de nitrogênio aplicadas, evidenciando que a produção de matéria seca pelo meloeiro tende a reduzir com a elevação das doses de nitrogênio e de potássio. Isto pode estar relacionado com a redução da área foliar, devido ao excesso de nitrogênio, como mostra os dados da Tabela 2, ou a desequilíbrios entre esses nutrientes, afetando a produção de foto-assimilados, tal como apresentaram Bhela \& Wilcox (1986), quando discorreram sobre a relação do aumento da área foliar com a produção de fotoassimilados.
A área foliar foi significativamente influenciada $(\mathrm{P}<0,01)$ apenas pelas doses de nitrogênio. Pelos dados apresentados na Tabela 2, vê-se que a área foliar decresceu com o aumento das doses de nitrogênio. O maior valor de área foliar do meloeiro $\left(12.017,40 \mathrm{~cm}^{2}\right.$ planta-1 $)$ foi obtido com a aplicação de $100 \mathrm{~kg} \mathrm{ha}^{-1}$ de $\mathrm{N}$; no entanto, foi diferente apenas daquele obtido com a maior dose de $\mathrm{K}_{2} \mathrm{O}$. Bhela \& Wilcox (1989) verificaram aumento da área foliar do meloeiro com a elevação da dose de nitrogênio em até $67 \mathrm{~kg} \mathrm{ha}^{-1}$ de N. Quando a quantidade aplicada foi de $100 \mathrm{~kg} \mathrm{ha}^{-1}$ de $\mathrm{N}$, ocorreu tendência na redução da área foliar dessa cultura, o que está de acordo com os resultados deste trabalho e sugere que doses de nitrogênio acima de $100 \mathrm{~kg} \mathrm{ha}^{-1}$ de $\mathrm{N}$ afetam o crescimento da área foliar do meloeiro, influenciando a produtividade e a qualidade de frutos.

Tabela 2. Valores médios de área foliar $\left(\mathrm{cm}^{2}\right.$ planta-1 $)$ do meloeiro sob diferentes doses de nitrogênio aplicadas por gotejamento

Doses de $\mathrm{N}\left(\mathrm{kg} \mathrm{ha}^{-1}\right) \quad$ Área foliar $\left(\mathrm{cm}^{2}\right.$ planta $\left.^{-1}\right)$

\begin{tabular}{cc}
\hline 100 & $12.017,40 \mathrm{a}$ \\
160 & $11.406,20 \mathrm{a}$ \\
220 & $10.390,30 \mathrm{ab}$ \\
280 & $7.735,50 \mathrm{~b}$ \\
\hline${ }^{*}$ Médias seguidas de letras iguais não diferem $(\mathrm{P}>0,01) ; \mathrm{CV}=20,07 \%$
\end{tabular}

A análise de variância revelou efeito significativo $(\mathrm{P}<0,01)$ das doses de nitrogênio e de potássio e sua interação sobre o peso médio de frutos do meloeiro, cujos valores variaram de $1,44 \mathrm{~kg}\left(220 \mathrm{~kg} \mathrm{ha}^{-1}\right.$ de N e $370 \mathrm{~kg} \mathrm{ha}^{-1}$ de $\left.\mathrm{K}_{2} \mathrm{O}\right)$ a $1,85 \mathrm{~kg}(220 \mathrm{~kg}$ $\mathrm{ha}^{-1}$ de $\mathrm{N}$ e $190 \mathrm{~kg} \mathrm{ha}^{-1}$ de $\mathrm{K}_{2} \mathrm{O}$ ). Pela comparação de médias (Tabela 3) para as doses de potássio 100 e $280 \mathrm{~kg} \mathrm{ha}^{-1}$ e peso médio de frutos, não se constatou diferença entre as dosagens de nitrogênio aplicadas; já para as demais doses de potássio, diferenças entre os valores de peso médio de frutos com as doses de nitrogênio, foram constatadas.

As variações de peso médio de frutos entre as doses de potássio só foram verificadas quando combinadas com 100 e 220 $\mathrm{kg} \mathrm{ha}^{-1}$ de N; no entanto, somente com a aplicação de $100 \mathrm{~kg} \mathrm{ha}^{-1}$ de $\mathrm{N}$ se constatou que o peso médio de frutos aumentou com a elevação das doses de potássio, o que está em acordo com Jassal et al. (1971) e Brantley \& Warren (1961). Com a aplicação de 100 $\mathrm{kg} \mathrm{ha}^{-1} \mathrm{de} \mathrm{N}$, o maior valor de peso médio $(1,84 \mathrm{~kg})$ foi superior apenas ao valor obtido com $100 \mathrm{~kg} \mathrm{ha}^{-1} \mathrm{de}_{2} \mathrm{O}$. Desta forma, o aumento do peso médio de frutos do meloeiro com a elevação das doses de potássio crescentes pode estar relacionado com a função do potássio na translocação dos carboidratos para os frutos, elevando seu peso (Prabhakar et al., 1985).

Tabela 3. Valores médios* de peso médio de frutos do meloeiro $(\mathrm{kg})$ sob diferentes doses de nitrogênio e potássio, aplicadas por gotejamento

\begin{tabular}{ccccc}
\hline Dosagens de & \multicolumn{4}{c}{ Dosagens de $\mathrm{K}_{2} \mathrm{O}\left(\mathrm{kg} \mathrm{ha}^{-1}\right)$} \\
\cline { 2 - 5 } $\mathrm{N}\left(\mathrm{kg} \mathrm{ha}^{-1}\right)$ & 100 & 190 & 280 & 370 \\
\hline 100 & $1,51 \mathrm{Ba}$ & $1,59 \mathrm{Aab}$ & $1,79 \mathrm{ABa}$ & $1,84 \mathrm{Aa}$ \\
160 & $1,73 \mathrm{Aa}$ & $1,80 \mathrm{Aab}$ & $1,67 \mathrm{Aa}$ & $1,84 \mathrm{Aa}$ \\
220 & $1,53 \mathrm{Ba}$ & $1,85 \mathrm{Aa}$ & $1,58 \mathrm{Ba}$ & $1,44 \mathrm{Bb}$ \\
280 & $1,53 \mathrm{Aa}$ & $1,56 \mathrm{Ab}$ & $1,68 \mathrm{Aa}$ & $1,57 \mathrm{Ab}$ \\
\hline *Médias seguidas de letras maí́sculas iguais na horizontal e as seguidas de letras minúsculas na \\
vertical, não diferem $(\mathrm{P}>0,01) ; \mathrm{CV}=4,09 \%$
\end{tabular}


Em relação ao efeito de nitrogênio no peso médio de frutos do meloeiro, autores como Srinivas \& Prabhakar (1984), Prabhakar et al. (1985) e Faria et al. (1994) destacam que o nitrogênio exerce efeito benéfico no peso médio de frutos do meloeiro; contudo, as doses elevadas e o desequilíbrio com outros nutrientes podem afetar negativamente o peso de frutos. Faria et al. (2000) verificaram, ao testarem as doses de 0, 80, 130 e $180 \mathrm{~kg} \mathrm{ha}^{-1}$ de $\mathrm{N}$, aumento de peso de frutos de meloeiro com a elevação das doses de nitrogênio mas com menor densidade de plantas, o peso de frutos obtidos com $130 \mathrm{~kg} \mathrm{ha}^{-1}$ de $\mathrm{N}$ não foi diferente do registrado com $180 \mathrm{~kg} \mathrm{ha}^{-1}$ de N. Em uma situação de maior densidade de plantio, o peso de frutos não aumentou quando se elevou de 80 para $180 \mathrm{~kg} \mathrm{ha}^{-1} \mathrm{de} \mathrm{N}$. Neste trabalho, verifica-se comportamento semelhante, porém com tendências variadas, em função das combinações com diferentes doses de potássio, pois com $190 \mathrm{~kg} \mathrm{ha}^{-1}$ de $\mathrm{K}_{2} \mathrm{O}$ o peso de frutos aumentou até a aplicação de $220 \mathrm{~kg} \mathrm{ha}^{-1} \mathrm{de} \mathrm{N}$, porém não significativo, o que não ocorreu com as demais doses de potássio.

Os valores obtidos de peso de frutos em função das doses de nitrogênio e de potássio tiveram baixo coeficiente de variação $(\mathrm{CV}=4,09 \%)$ mostrando pouca variação entre os dados e, de maneira geral, foram superiores aos obtidos por Sousa \& Sousa (1998) com a mesma cultivar e próximos dos registrados por Faria et al. (2000).

A produtividade comercial do meloeiro foi significativamente $(\mathrm{P}<0,01)$ influenciada pelas doses de nitrogênio e potássio e a interação entre elas. A maior produtividade do meloeiro $(48,13$ $\mathrm{t} \mathrm{ha}^{-1}$ ) foi obtida com a aplicação de $100 \mathrm{~kg} \mathrm{ha}^{-1}$ de N e $370 \mathrm{~kg} \mathrm{ha}^{-}$ ${ }^{1}$ de $\mathrm{K}_{2} \mathrm{O}$, que foi estatisticamente superior às demais produtividades obtidas com as diferentes doses de potássio, considerando-se a dose de $100 \mathrm{~kg} \mathrm{ha}^{-1} \mathrm{de} \mathrm{N}$. Quando variaram as doses de nitrogênio, a máxima produtividade foi superior àquelas obtidas com a aplicação de 220 e $280 \mathrm{~kg} \mathrm{ha}^{-1}$ de $\mathrm{N}$ (Tabela 4).

Ainda pela Tabela 4, a fertirrigação com $220 \mathrm{~kg} \mathrm{ha}^{-1}$ de N e $100 \mathrm{~kg} \mathrm{ha}^{-1}$ de $\mathrm{K}_{2} \mathrm{O}$ proporcionou a menor produtividade comercial do meloeiro $\left(22,36 \mathrm{t} \mathrm{ha}^{-1}\right)$, que foi significativamente inferior às produtividades obtidas com as combinações de 100 $\mathrm{kg} \mathrm{ha}^{-1}$ de $\mathrm{K}_{2} \mathrm{O}$, com 100, 160 e $280 \mathrm{~kg} \mathrm{ha}^{-1}$ de $\mathrm{N}$ e àquelas registradas com as combinações das demais doses de potássio com $220 \mathrm{~kg} \mathrm{ha}^{-1}$ de N.

Verificou-se tendência na redução da produtividade comercial do meloeiro com a aplicação de doses de nitrogênio acima de $220 \mathrm{~kg} \mathrm{ha}^{-1} \mathrm{de} \mathrm{N}$, ficando mais caracterizado quando

Tabela 4. Produtividade comercial $\left(\mathrm{t} \mathrm{ha}^{-1}\right)$ do meloeiro sob diferentes dosagens de nitrogênio e de potássio aplicadas por gotejamento

\begin{tabular}{ccccc}
\hline Dosagens de & \multicolumn{4}{c}{ Dosagens de $\mathrm{K}_{2} \mathrm{O}\left(\mathrm{t} \mathrm{ha}^{-1}\right)$} \\
\cline { 2 - 5 } $\mathrm{N}\left(\mathrm{t} \mathrm{ha}^{-1}\right)$ & 100 & 190 & 280 & 370 \\
\hline 100 & $33,49 \mathrm{Ba}$ & $33,88 \mathrm{Bab}$ & $37,21 \mathrm{Bab}$ & $48,13 \mathrm{Aa}$ \\
160 & $36,67 \mathrm{Ba}$ & $37,86 \mathrm{ABa}$ & $41,15 \mathrm{ABa}$ & $45,37 \mathrm{Aab}$ \\
220 & $22,36 \mathrm{Bb}$ & $37,32 \mathrm{Aab}$ & $31,43 \mathrm{Ab}$ & $36,90 \mathrm{Ab}$ \\
280 & $31,95 \mathrm{Aa}$ & $29,41 \mathrm{Ab}$ & $31,53 \mathrm{Ab}$ & $29,90 \mathrm{Abc}$ \\
\hline \\
Médias seguidas de letras maiúsculas iguais na horizontal e as seguidas de letras minúsculas na \\
vertical, não diferem $(\mathrm{P}>$ 0,01); $\mathrm{CV}=6,08$
\end{tabular}

combinadas com a máxima dose de potássio $\left(370 \mathrm{~kg} \mathrm{ha}^{-1} \mathrm{de}\right.$ $\mathrm{K}_{2} \mathrm{O}$ ), cuja redução da produtividade ocorreu a medida em que se aumentou a quantidade de nitrogênio aplicada. Como se observa, com a aplicação de 100 e $160 \mathrm{~kg} \mathrm{ha}^{-1}$ de N, a produtividade do meloeiro tendeu a aumentar sempre que se elevaram as doses de potássio, tendência esta não observada quando as doses de nitrogênio foram superiores a $220 \mathrm{~kg} \mathrm{ha}^{-1}$.

A redução da produtividade comercial com a aplicação de doses de nitrogênio acima de $160 \mathrm{~kg} \mathrm{ha}^{-1}$ pode estar relacionada ao efeito do excesso desse elemento no metabolismo das plantas e na produção de foto assimilados, tal como foi verificado no acúmulo de matéria seca. Resultados semelhantes foram obtidos por Pinto et al. (1997) quando observaram que com a aplicação de nitrogênio por fertirrigação acima de $129 \mathrm{~kg}$ $\mathrm{ha}^{-1}$ de $\mathrm{N}$, a produtividade do meloeiro tendeu a reduzir, concordando com Bhella \& Wilcox (1986), Bhella \& Wilcox (1989) e Suarez (1991), em relação à tendência, porém divergem quanto às dosagens, uma vez que esses autores notaram redução da produtividade do meloeiro com doses entre $67 \mathrm{e}$ $100 \mathrm{~kg} \mathrm{ha}^{-1}$ de N; Faria et al. (2000) ao testarem o efeito de doses de nitrogênio por fertirrigação e densidade de plantio no meloeiro, constataram aumento da produtividade com a elevação da quantidade de até $180 \mathrm{~kg} \mathrm{ha}^{-1}$ de $\mathrm{N}$.

A elevação da produtividade do meloeiro com a quantidade de potássio aplicada por fertirrigação está associada ao aumento do peso médio de frutos, uma vez que este elemento exerce importante papel na translocação de carboidratos para os frutos (Prabhakar et al., 1985). Jassal et al. (1971) encontraram influência do potássio no aumento do peso de frutos e na produtividade do meloeiro, cujo comportamento está de acordo com os resultados obtidos neste trabalho.

\section{CONCLUSÕES}

1. A matéria seca, o peso médio de frutos e a produtividade comercial do meloeiro, são influenciados pelas doses de nitrogênio e potássio e pela interação entre elas, enquanto a área foliar é influenciada apenas pelas doses de nitrogênio.

2. A produtividade do meloeiro tende a reduzir com as combinações de doses elevadas de nitrogênio e potássio.

\section{LITERATURA CITADA}

Bastos, E.A.; Rodrigues, B.H.N.; Andrade Júnior, A.S de. Dados agrometeorológicos para o município de Parnaíba, PI (19901999). Teresina: EMBRAPA Meio-Norte. 2000. 27p. Documentos, 46

Belfort, C.C. Acumulação de matéria seca e recrutamento de nutrientes em melão (Cucumis melo L. cv Valenciano Amarelo CAC) cultivado em Llatossolo Vermelho amarelo em Presidente Wenceslau-SP. Piracicaba: ESALQ, 1985. 72p. Tese Doutorado

Benincasa, M.M.P. Análise de crescimento de plantas: noções básicas. Jaboticabal: FUNEP, 1988. 42p. 
Bhella, H.S.; Wilcox, G.E. Yield and composition of muskmelon as influenced by preplant and trickle applied nitrogen. Hortscience, Alexandria, v.21, n.1, p.86-88, 1986.

Bhella, H.S.; Wilcox, G.E. Lime and nitrogen influence soil acidity nutritional status, vegetative growth, and yield of muskmelon. Journal of the American Society for Horticultural Science, Alexandria, v.114, n.2, p.606-610, 1989.

Brantley, B.B.; Warren, G.F. Effect of nitrogen nutrition on flowering, fruiting and quality in the muskmelon. Proceedings of American Society Horticulture Science. Alexandria, v.77, n.1, p.424-431, 1961.

Doorenbos, J.; Pruitt, W.O. Las necesidades de agua de los cultivos. Roma: FAO. 1984. 194 p. FAO. Riego y Drenaje, 24.

EMBRAPA. Empresa Brasileira de Pesquisa Agropecuária. Sistema brasileiro de classificação de solos. Brasília: Embrapa Produção de Informação; Rio de Janeiro: Embrapa Solos, 1999. 412p.

Faria, C.M.B. de. Nutrição mineral e adubação da cultura do melão. Petrolina, PE: EMBRAPA-CPATSA, 1990, 26p. Circular Técnica, 22

Faria, C.M.B. de; Costa, N.D.; Pinto, J.M.; Brito, L.T. de O.; Soares, J.M. Níveis de nitrogênio por fertirrigação e densidade de plantio na cultura do meloeiro em um Vertissolo. Pesquisa Agropecuária Brasileira, Brasília, v.35, n.3, p.491-495, 2000.

Faria, C.M.B. de; Pereira, J.R.; Possídio, E.L. Adubação orgânica e mineral na cultura do melão em um vertissolo do Submédio São Francisco. Pesquisa Agropecuária Brasileira, Brasília, v.29, n.2, p.191-197, 1994.

Graifenberg, A.; Petsas, S. Growth and uptake in melon. Horticultural Abstracts, Wallingford, v.54, n.2, p.169, 1983.

Hernandez, C.F.; ASO, P.J. Fertilización del melón en invernadero. Avance Agroindustrial, Tuaiman, La Plata, v.12, n.47, p.3-4, 1991.
Jassal, N.S.; Randhawa, K.S. Nanddpuri, K.S. A study on the effect of irrigation and certain doses of $\mathrm{N}, \mathrm{P}$ and $\mathrm{K}$ on the weight of fruit yield of muskmelon (Cucumis melo L.), Horticultural Abstract, Wallingford, v.41, n.2, p.1066, 1971.

Katayama, M. Nutrição e adubação de melão e melancia. In: Simpósio Sobre Nutrição e Adubação de Hortaliças, 1990, Jaboticabal. Anais... Piracicaba: Associação Brasileira para Pesquisa da Potassa e do Fósforo, 1993. p.219-226.

Pinto, J.M.; Brotel, T.A.; Feitosa Filho, J.C. Efeitos do nitrogênio via fertirrigação na cultura do melão. Engenharia Agrícola, Jaboticabal, v.16, n.4, p.27-35, 1997.

Prabhakar, B.S.; Srinivas, K.; Shukla, V. Yield and quality of muskmelon (cv Haro madhu) in relation to spacing and fertilization. Progressive Horticultural, Chaubattia, v.17, n.1, p.51-5, 1985.

Sousa, V.F. de. Freqüência de aplicação de N e K via água de irrigação por gotejamento no meloeiro (Cucumis melo L. cv. Eldorado 300) em solo de textura arenosa. Botucatu: UNESP, 1993. 131p. Dissertação Mestrado

Sousa, V.F. de Sousa, A. de P. Efeitos de freqüência de aplicação de $\mathrm{N}$ e $\mathrm{K}$ por gotejamento na cultura do meloeiro (Cucumis melo L.). Engenharia Agrícola, Sorocaba, v.17, n.3, p.36-45, 1998.

Srinivas, K.; Prabhakar, B.S. Response of muskmelon (Cucumis melo $\mathrm{L}$.) to varying levels of spacing and fertilizers. Singapore Journal of Primary Industries, Singapore, v.12, n.1, p.56-61, 1994.

Suarez, D.F. Demanda de nitrógeno y eficiencia de la fertilización de melón reticulado (Cucumis melo L. var reticulatus Naud). Ciencia e Investigación Agraria, Santiago, v.18, n.3, p. 101110, 1991.

Tyler, K.B.; Lorenz, O.A. Nutrient absorption and growth of four muskmelon varieties. Journal of the American Society for Horticultural Science, Alexandria, v.84, p.191-195, 1964.

Williams, C.N. Fertilizer responses of cumcubers on peat in Brunei. Experimental. Agriculture, Cambridge, v.14, p. 299 302,1978 . 